\title{
Child Support Judgments: \\ Comparing Public Policy to the Public’s Policy
}

by

Ira Mark Ellman,*+ Stephen McKay, ${ }^{* *}$ Joanna Miles, ${ }^{* * *}$ and Caroline Bryson****

\author{
*College of Law and Department of Psychology, Arizona State University, USA, ** School of \\ Social and Political Sciences, University of Lincoln, UK, *** Trinity College, University of \\ Cambridge, UK, **** Bryson Purdon Social Research \\ +Corresponding Author: Email: ira@asu.edu
}

\begin{abstract}
Any child support regime necessarily makes policy choices about how parental income should be shared between the two parental households. Those choices involve balancing the claims of the child, the claims of the custodial parent for help with the expense of providing for the child, and the claims of the support obligor for autonomy in deciding how to spend his own earnings. That balancing task is complicated by the fact that the child and the custodial parent necessarily share a living standard, so that any child support transfer, large or small, will unavoidably benefit the custodial parent as well as the child. This article reports the findings of an empirical study designed to reveal how the British public believe this balance should be struck. It then compares the public's preferred policies to the policy choices implicit in the current UK child support schedule. It concludes that there are important gaps between the two, and recommends that consideration be given to amending the current UK law to better align it with the public's values | on these matters. ${ }^{+1}$
\end{abstract}

\footnotetext{
${ }^{1}$ The authers thank Sharon Witherspoon, Teresa Williams and the Trustees of the Nuffield Foundation (Ww nuffieldfoundation.org) for their support and funding of the study. The views expressed are those of the authors alone, and do not necessarily represent those of the Foundation. We also thank the British Social Attitudes team at NatCen Social Research, as well as, of course, all the sumey respondents who took the time to answer our questions. Part of McKay's pork took place whilst at the University of Birmingham, UK, and part of Ellman's whilst he was a Visiting Fellow at Trinity College, Gambridge-

$\S$ The authors thank Sharon Witherspoon, Teresa Williams and the Trustees of the Nuffield Foundation (www.nuffieldfoundation.org) for their support and funding of the study. The views expressed are those of the authors alone, and do not necessarily represent those of the Foundation. We also thank the British Social Attitudes team at NatCen Social Research, as well as, of course, all the survey respondents who took the time to answer our questions. Part of McKay's work took place whilst at the University of Birmingham, UK, and part of Ellman's whilst he was a Visiting Fellow at Trinity College, Cambridge.
} 


\section{INTRODUCTION}

Successive British governments have tried different approaches to ensure that non-resident parents fulfil their child support obligations. With the establishment of the Child Support Agency (CSA) in 1993, responsibility for both setting required child support amounts, and enforcing the requirement, was taken from the courts in almost all cases. Parents with care (resident parents) receiving means-tested state benefits were obliged to use the CSA's services, unless able to show a 'good cause' not to do so, and the state recouped the amount of their benefits from the support paid. Other parents could use the CSA, make a private arrangement between them, or do nothing (by design or default). ${ }^{1}$

Despite repeated attempts to improve the CSA's efficiency, including by substantial simplification of the formula for calculating child support liability in 2003, the CSA failed to ensure that all, or even most, fathers met their child support obligations. A large-scale administrative overhaul of the system between 2006 and 2009 and a reduced caseload (resulting from the 2008 repeal of the requirement that mothers on means-tested benefits use the CSA), produced some improvements in the CSA's performance. ${ }^{2}$ By 2006, and arguably well before, there was widespread recognition that the CSA was a failed institution and that major change was needed. ${ }^{3}$ The Child Maintenance and Other Payments Act 2008 created a new statutory child support scheme, run by a new body to replace the CSA. Various changes - outlined below - were made with a view to making the system easier and more cost-effective to operate. The Coalition Government largely inherited this programme for change, which it started to roll-out on a very limited basis for new applicants from December 2012. Completion (when all cases will be run by a new 'Child Maintenance Service') is expected to be in 2017.

The current statutory formula for calculating child support, applicable to most existing cases, has been used since 2003. It achieved simplicity in part by eliminating consideration of the mother's income. ${ }^{4}$ Child support is instead set at a percentage of the father's net income that varies only with the number of children, without regard to the mother's income: 15 per cent for one child, 20 per cent for two children, and 25 per cent for three or more children. A downward adjustment is made when the father or his current partner have other dependent children. The support obligation is also reduced if the children stay with the father at least 52 nights each year. 
The 2003 formula also eliminated consideration of the income of either parent's new partner, which the earlier formula had taken into account, although not in entirely transparent ways. In due course the revised system will be simplified further by basing the calculation on the father's gross taxable $e^{5}$ income from the previous tax year, rather than on his net income for the current year. This will enable the father's relevant income to be established by reference to the past year's tax return, potentially easing the difficulties of proving income in some complex cases, such as those involving self-employed fathers. There is no intention to alter the schedule in substance, however, as the percentages applied to the gross income will be adjusted so as to produce support amounts roughly comparable to those now required. ${ }^{6}$

The main administrative changes now being implemented by the Coalition Government aim to move parents to make their own 'family-based arrangements' rather than use the statutory system. Based on recommendations from Sir David Henshaw's 2006 report, ${ }^{7}$ mothers will be charged an upfront fee (£20) for invoking the statutory child support service, and both parents (but especially the father, with a 20 per cent fee) will be charged significant ongoing fees if the government collects support payments. Even parents willing to pay for use of the statutory system will not have access to it without first participating in a conversation with a governmentfunded body, the Child Maintenance Options Service, intended to help them make family-based arrangements.

We previously reported that the planned move away from government setting and enforcing child support obligations appears contrary to the views of the British public, as revealed in attitude questions we put in the 2012 British Social Attitudes (BSA) survey (Bryson, Ellman, McKay and Miles, 2014). But knowing only that the public supports government enforcement of child support leaves crucial questions unanswered: how much support do they believe the government should require of non-resident parents, and what principles do they believe should apply in setting that amount? Our earlier article shed some light on these questions by summarizing some results from other questions we also put on that BSA survey. In these questions, respondents were asked to state the child support amount they would require in particular cases put to them. This article provides a much fuller examination of those data. We ask whether the public's answers establish their endorsement of any particular principles for setting support amounts, and if so, whether the public's views are consistent with the current UK statutory formula. Not surprisingly, there is no clear public consensus about the precise support 
amount, in pounds, the government should require in any particular case. Yet it is equally clear from the data that there are basic principles for setting that amount that enjoy wide public support, and, as we explain below, the method current UK law uses to set support amounts is inconsistent with those principles. We therefore conclude that a re-examination of the current law's rationale is in order.

\section{METHOD}

\section{What Survey Respondents Were Asked}

This study presented a series of cases (vignettes) in face-to-face interviews with individuals in a large representative sample of the British population. The method was based on an approach used by one of the authors in a successful series of studies in the United States (Ellman, Braver and MacCoun, 2009; Braver, Ellman, and MacCoun, 2014). British survey respondents were asked to imagine that they were responsible for setting the amount of child support the law should require the father to pay the mother in each of the cases. They were told to state the amount they believed the law 'should' require. They were not asked to guess what the law in fact requires. They were told there was 'no right or wrong answer' because we just 'want to know what you think', and they were not asked to explain their answers. They were thus free to apply whatever unarticulated principles they saw fit. The complete text of the basic question is set out in the box below. 


\section{Text of Question on Child Support Judgements.}

Usually when parents don't live together, their children live mainly with one parent. By law, the other parent should pay child maintenance to the parent with whom the child lives most of the time. But the question is how much maintenance the law should require the other parent to pay. There are no right or wrong answers on this. We want to know what you think the law should require.

I'm going to tell you about several different situations, and ask you to imagine that you are the person who has to decide how much maintenance the law should require the parent to pay in each case. We want you to tell us what you think the amount should be.

I want you to imagine a family in which -

There is one child, an 8 year old boy;

His parents were married for 10 years, but are now divorced;

He lives mostly with his mother, but sees his father twice a week after school, and usually stays with his father overnight once at the weekend.

This text remained unchanged across the cases, and thus for every case the parents were divorcing after ten years of marriage, and had one child, an eight year old boy, who now lives primarily with mother but sees father on the indicated schedule. What did vary across the cases were the parents' incomes. There were three variants of the father's 'net monthly income ${ }^{8}$ (£1,000, £2,000 or $£ 3,000$ a month) and three of the mother's (£900, £1,500, or £2,200). ${ }^{9}$ There were thus nine $(3 \times 3)$ possible income combinations, and thus nine possible cases. Every respondent was asked to state in pounds the monthly amount of child support they would require the law to set in each of the nine cases. Respondents could consult their answer for a prior case, if they wished, before responding to a later case. They were free to propose amounts that varied, or did not vary, from vignette to vignette. Pilot studies for the American work found that respondents' answers were affected by the sequence in which the income-combinations were given; we therefore adopted the American approach and presented the cases in four different counterbalanced orders that were randomly employed among respondents. All results reported in this article are aggregated across these four orders. ${ }^{10}$ As a control device, a different and smaller group of respondents was presented with a set of questions identical to those we report on here, but for one change in the wording: instead of being asked what they thought the law should 
require the father to pay, this group was asked to state the amount they believed it was fair for the father to pay. ${ }^{11}$

\section{The Sample}

Our questions formed one of six substantive modules in the 2012 British Social Attitudes Survey (BSA). ${ }^{12}$ This high quality, representative sample survey has been conducted by NatCen Social Research in most years since $1983 .{ }^{13}$ While the authors were responsible for constructing the questions in their module, they worked in consultation with NatCen to ensure that the module could be administered effectively by the NatCen interviewers, and the team made some adjustments to the module following pilot studies conducted by NatCen.

The BSA survey series puts questions to a large representative sample of British adults aged 18+. Since 1993, the sampling frame for the survey has been the Postcode Address File (PAF), which is a list of addresses (or postal delivery points) compiled by the Post Office. The sampling method is a multi-stage design, with three separate stages of selection: postcode sector (e.g. 'B15 2'), address, and individual, with one individual selected at each address. The structure of the questionnaire plus further technical details of the survey series can be found at www.natcen.ac.uk/bsa.

Interviewing for the 2012 BSA mainly took place between June and September of that year, with a small number of interviews in October and November. Fieldwork was conducted by interviewers drawn from NatCen's regular panel, using face-to-face computer-assisted personal interviewing (CAPI). Some BSA questions are included in a pen and paper self-completion section, fielded in addition to the main interview, but this article reports on questions that were part of the face-to-face survey. There were 2,984 interviews putting the question set forth in the box above, albeit with item-missing data on particular questions (mostly low levels). ${ }^{14}$ The overall survey response rate was 53 per cent. The sampling weights for BSA correct for the unequal selection of addresses, dwelling units and individuals. There is also correction for biases caused by differential non-response with the final non-response weight designed so that the weighted sample matches the population in terms of age, sex and region. A technical section on the BSA website provides further details for the 2012 survey in particular (http://www.bsa- 
30.natcen.ac.uk/read-the-report/technical-details.aspx). However, in general terms we can expect that the achieved sample, suitably weighted, is a good representation of the population aged 18+ in Great Britain (England, Wales and Scotland).

\section{RESULTS}

We reported our respondents' mean child support amounts, and their distribution, in Bryson et al. (2013). We first briefly review and expand upon that data here, and then employ statistical modelling techniques to enable us to obtain a deeper understanding of respondents' beliefs.

\section{Means and variability in child support amounts}

Figure 1 displays the mean monthly child support amounts our respondents believed the law should require the father to pay for each of the nine cases put to them. There is a separate line for each of the three maternal incomes. The father's income is on the horizontal axis, with child support amounts on the vertical axis. The data markers show the mean amount specified for each of the nine combinations of mother's and father's income. A line joining the markers for each maternal income helps reveal the response pattern. A fourth line indicates the support amount currently set for these same nine cases by the child support legislation under the CSA 2003 system. One line is sufficient because the legislative schedule does not vary with maternal incomes. 
Figure 1 Mean monthly child support amount favoured by respondents for different levels of net monthly parental income, and statutory (CSA 2003 system) amounts

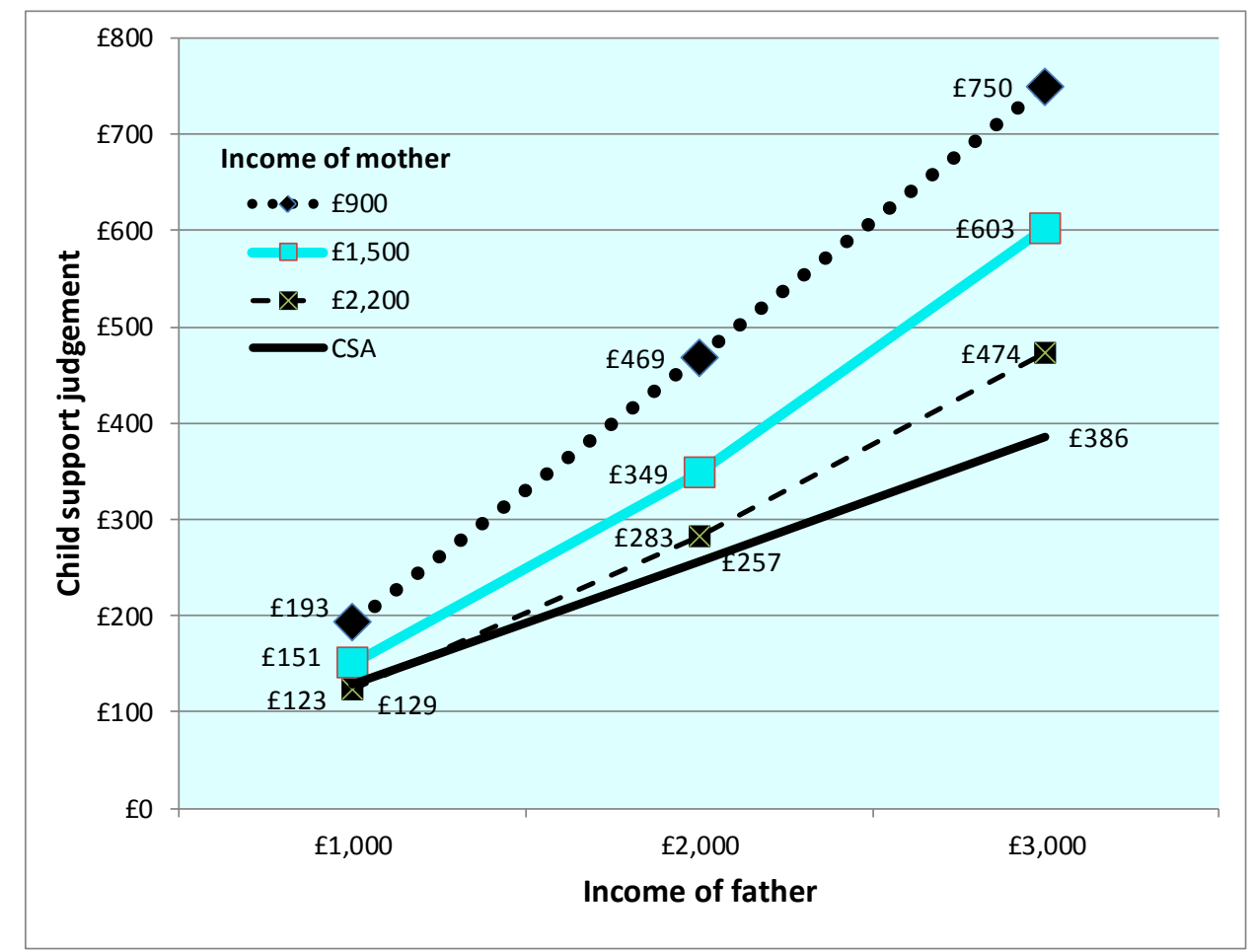

This figure reveals four key points about the public's beliefs. First, they believe the mother's income matters. If they thought it did not matter, their views would display as one line instead of three, because the three lines would be on top of one another. Because they are not on top of each other we know the public believes thinks support amounts should vary with maternal income. ${ }^{15}$ Second, the fact that all three lines rise as they move to the right shows the public believes fathers who earn more should pay more child support. Whilst this might seem obvious, closer examination reveals a more subtle point: the lines also 'fan out' as the father's income increases, because the slope of the lines is steeper for cases in which the mother's income is lower. That shows the public believes the father's obligation should increase more rapidly with his income when the mother's income is lower. For example, when the mother earns $£ 2,200$ a month, our respondents require fathers to pay an additional $£ 18$ for each additional $£ 100$ of their income, but they require fathers to pay $£ 23$ per additional $£ 100$ of their income when the mother's earns $£ 1,500$ a month, and $£ 28$ per $£ 100$ when she earns only $£ 900$. Finally, and third, it 
appears the public does not believe the function of child support is limited to lifting children out of poverty, because they would require maintenance payments to keep rising with the father's income beyond the point at which poverty would be alleviated. The difference between the maintenance they would require of the father earning £2,000 and the higher amount they would require of the father earning $£ 3,000$ suggests they think the higher-income father should help pay for some amenities in the mother's household, not just necessities. ${ }^{16}$ These same three features were also found in the pattern of responses in the American studies, and were summarized as the data's 'fanning line pattern' because the three lines all rise but also fan out (Ellman, Braver and MacCoun, 2014). We adopt that label here.

The fourth point that is also evident from Figure 1 is that for eight of the nine cases put to them, the public would require fathers to pay higher amounts than called for in the CSA schedule. ${ }^{17}$ The only exception is the case combining the lowest paternal income with the highest maternal income, for which the mean preference of the public is essentially identical to the CSA schedule. The exception, however, is actually an example of a consistent pattern: the gap between the public's view and current UK law increases when the father's income is higher, or the mother's income is lower. That increase in the gap is visually apparent in Figure 1. The difference at lower maternal incomes follows, of course, from the fact that the CSA schedule applies a flat percentage to paternal income that is the same for all maternal incomes, while our respondents would require fathers to pay a higher percentage of their income in child support when maternal incomes are lower.

Figure 2 is identical to Figure 1 except that our respondents' mean child support judgments for the nine income combinations are shown as a percentage of the father's income, rather than in pounds. Plotting the judgments as a percentage helps in comparing them to legislation, whether in the UK or elsewhere, that sets the presumptively correct support judgment as a percentage of parental income. The black horizontal line shows the percentage of income payable under the CSA schedule; as in Figure 1, a single line is sufficient because the law applies the same percentage no matter what the mother's income is, and the line is horizontal because the percentage does not vary with the father's income (within this income range ${ }^{18}$ ). It is clear from this figure that, on average, the British public disagrees with both these UK rules. Not only does the public favour raising the percentage applied to the father's income when the mother's income is lower, but they also prefer a progressive rate structure that increases the percentage of the 
father's income devoted to child support as his income increases. The upward slopes of the three data lines in Figure 2 show this, even though they are not steep. The point is made more clearly in Figure 3, which also plots support amounts as a percentage of the father's income. In Figure 3, however, each line represents a different paternal income, with maternal incomes indicated on the horizontal axis. Figure 3 thus shows how support varies with the mother's income, for any given paternal income. The downward slope reflects the public's view that the percentage should decline as the mother's income increases. The distance between the three sloping lines in Figure 3 reflects the public's preference for percentages that are higher for higher-income fathers.

Figure 2 Child support judgments as per cent of net monthly father income, for three different net monthly incomes of mother.

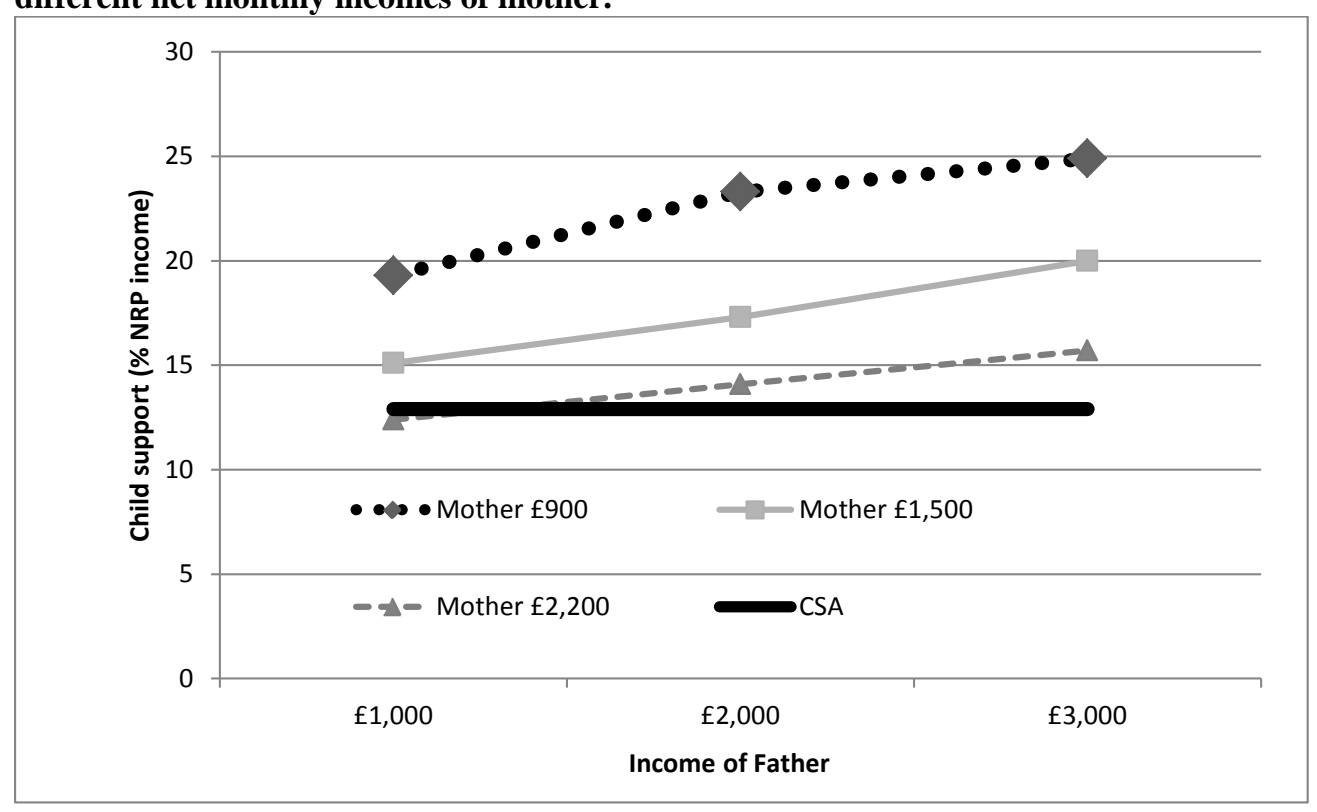


Figure 3 Child support judgments as per cent of father income (all incomes net monthly)

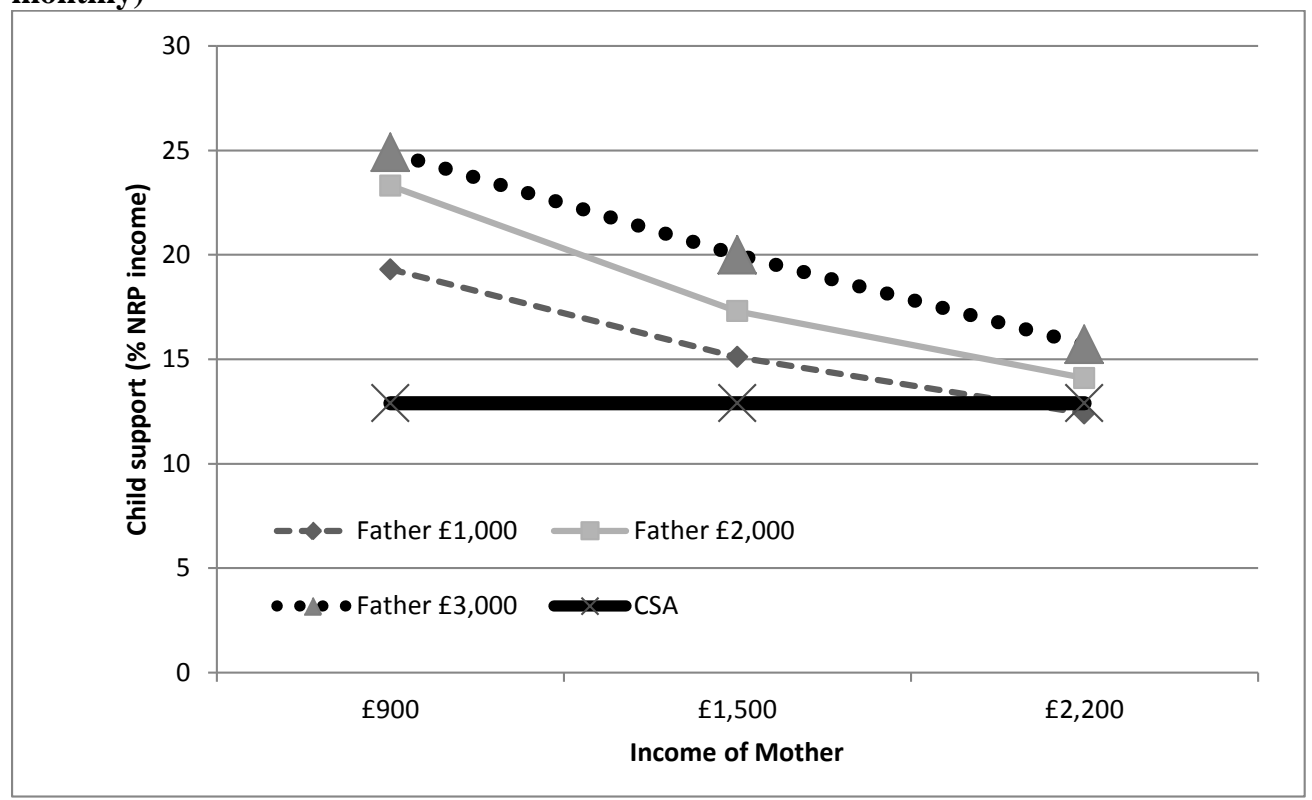

To this point we have focused on the average support amounts, but we also want to know how our respondents' judgments vary around the average. Table 1 shows, for all nine income combinations, the support amounts favoured by respondents at the $25^{\text {th }}$ and $75^{\text {th }}$ percentile, as well as the median ( $50^{\text {th }}$ percentile). So, where the father had an income of $£ 1,000$ and the mother an income of $£ 900$, the median suggestion was $£ 200$, but the lowest quarter of responses were $£ 100$ or less, whilst the most demanding quarter gave responses of $£ 250$ or more. Indeed, some support amounts favoured by the bottom quartile are quite low, such as $£ 10$ per month for the richest mother and poorest father. 
Table 1 Monthly child Support Judgements at differing points of the distribution and CSA amounts based on parental monthly incomes

\begin{tabular}{|c|c|c|c|c|c|c|c|c|c|c|c|c|}
\hline Father's & \multicolumn{4}{|c|}{$£ 1,000$} & \multicolumn{4}{|c|}{$£ 2,000$} & \multicolumn{4}{|c|}{$£ 3,000$} \\
\hline $\begin{array}{l}\text { Mother's } \\
\text { Income }\end{array}$ & CSA & $25^{\text {th }}$ & $50^{\text {th }}$ & $75^{\text {th }}$ & CSA & $25^{\text {th }}$ & $50^{\text {th }}$ & $75^{\text {th }}$ & CSA & $25^{\text {th }}$ & $50^{\text {th }}$ & $75^{\text {th }}$ \\
\hline$£ 900$ & 129 & 100 & 200 & 250 & 257 & 250 & 400 & 600 & 386 & 400 & 700 & 1000 \\
\hline$£ 1,500$ & 129 & 50 & 100 & 200 & 257 & 200 & 300 & 500 & 386 & 300 & 500 & 800 \\
\hline$£ 2,200$ & 129 & 10 & 100 & 200 & 257 & 100 & 200 & 400 & 386 & 200 & 400 & 600 \\
\hline
\end{tabular}

The overall pattern, however, is easier to see in Figure 4, which is like Figure 1 except that it plots the support amounts favoured by those whose child support judgments put them in the highest and lowest quartile, rather than the mean support amounts. The heavy black line lying at about the middle of the other six lines is the CSA amount. 
Figure 4. Mean child support judgments for respondents in the Upper and Lower quartiles (25/75), for each combination of net monthly parental incomes, and CSA amount.

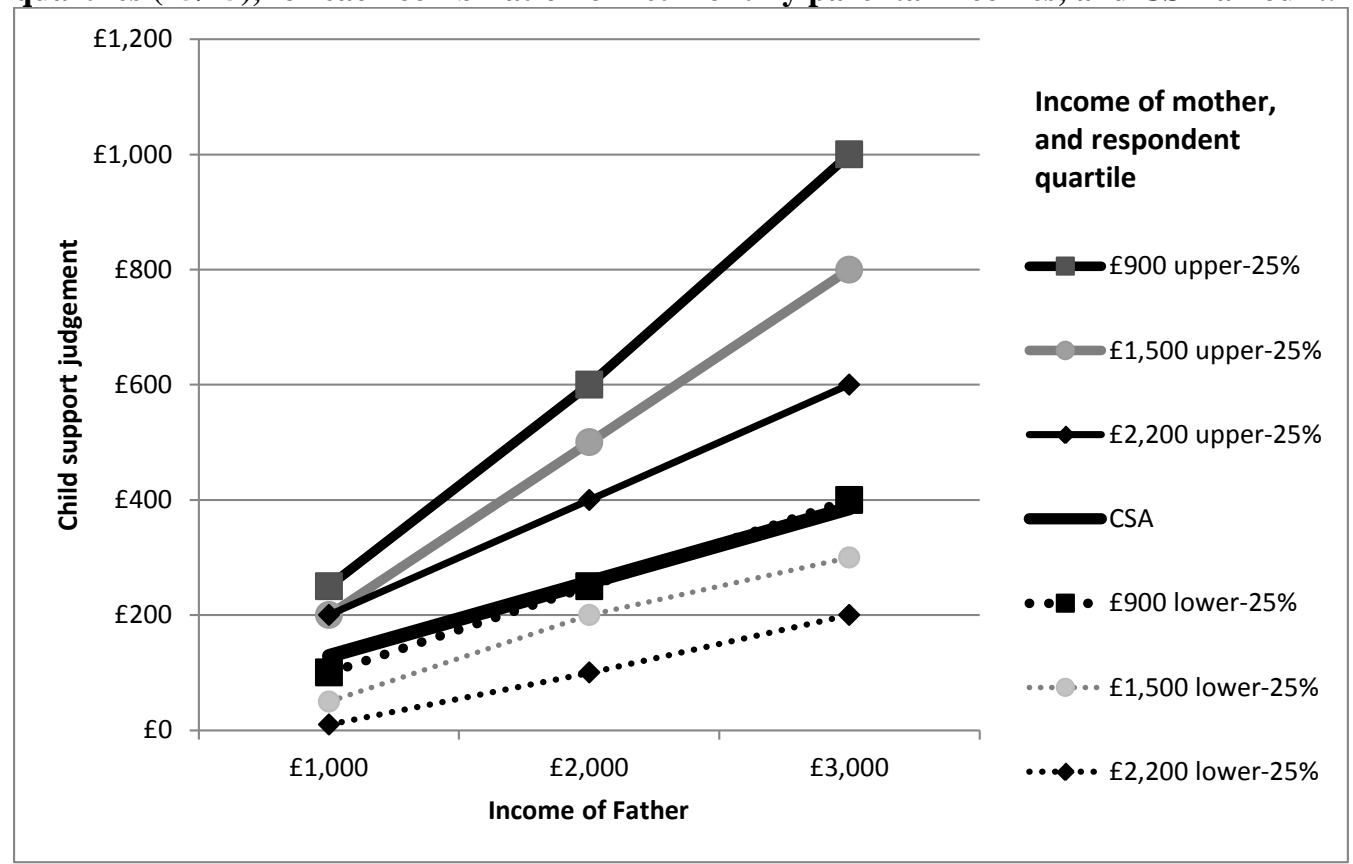

One can see that the support amounts favoured by the upper quartile are generally higher than the CSA amounts, and the divergence increases at higher father incomes. On the other hand, amounts favoured by the lower quartile fall at or below the CSA benchmark. So it seems there is considerable variability in the absolute support levels our respondents favour. Yet at the same time, the fanning line pattern shown in Figure 1 is also present in the responses of both the upper and lower quartiles. That is visually more apparent for the upper quartile because the slopes of those three lines are steeper than for the lower quartile responses, making it more obvious that their judgments grow further apart as father income rises. But that same pattern is also there for the lower quartile responses: the lines are closer together when father income is $£ 1000$ than when it is $£ 3000$. So even respondents in the lower quartile not only favour support amounts that are higher when the mother's income is lower, they also favour increasing support amounts more rapidly, with the father's income, when the mother's income is lower. For example, they would increase support amounts by $£ 150$ for each $£ 1000$ increase in paternal income, when maternal income is $£ 900$, but only by $£ 95$ per $£ 1000$ of paternal income, when maternal income is $£ 2,200$. 
Because of the steeper slopes generally, the equivalent amounts are further apart for the upper quartile--£375 and £200—-but a key point is that one gets the fanning line pattern in both groups.

\section{Developing a statistical model for the data.}

Generalizations about the public's views based only on the raw data presented thus far necessarily leave some important questions unanswered. That is because we obviously cannot present our questions to every member of the public, nor can we ask about everything that may affect their answers. We thus do not know the extent to which the answers we got depended on facts we did not ask about, and we do not know whether we might get different answers had we asked a different sample of the public. Moreover, the raw data cannot tell us much about how a particular respondent's characteristics affect that respondent's judgments in the cases-did it matter whether a respondent was a Conservative, or a woman, or a university graduate? Statistical models of the raw data can shed considerable light on all these questions. We provide an explanation of our methods in the boxed text below, cast in terms we hope is accessible to readers unfamiliar with statistical analysis. Readers who prefer to take us on faith may skip it.

The basic technique builds a model of the data using equations that set the dependent variable (here, the child support amount) as a function of the independent variables we investigated (here, the two parental incomes), adding an "error term” reflecting unexplained variation in the dependent variables that result from random fluctuation or from variables we did not ask about. Each independent variable in the equation is multiplied by its "coefficient". The analysis looks for coefficients that (in this case) give equations predicting a child support amount, for any combination of parental incomes, that come closest to the mean amount our respondents in fact chose for that case. Visually, we can use that equation to plot a line produced by the predicted support amounts for the cases, and we want the equation that produces the "best fit" line- the line that comes closest to the line created by plotting the actual data points for the nine cases put.

Such equations typically also have a "constant” term. In our case, imagine that we have a coefficient for each of the parental incomes, which tells us how much the predicted support amount (the amount predicted by our equation) varies as either parental income changes. But varies from what? One must have a starting point from which to adjust the support amount as either parent's income goes up or down. This is a constant because that starting point does not 
change from case to case- - the predicted support amount changes only because of changes in the value of the parental incomes.

A regression equation built the way we have just described would look like this:

$$
\text { CSJ }_{i j}=b_{0}+b_{1} \text { PWCIncome }_{j}+b_{2} \text { NRPIncome }_{j}+e_{i j}(1)
$$

What this says is that the child support judgment (CSJ) made by any particular individual respondent, $i$, for any given case $(j$ ) from among the 9 income combinations, is equal to a constant amount $\left(b_{0}\right)$ plus the PWC's income in case $j$ (PWCIncome ${ }_{j}$ ), multiplied by the coefficient for the PWC income $\left(b_{1}\right)$, added to the value of the NRP's income in that case multiplied by its coefficient $\left(b_{2}\right.$ NRPIncome $\left.e_{j}\right)$, plus the error term $\left(e_{i j}\right)$. Now of course, at this point in the process, we are not making distinctions among the individual respondents, so the child support amount being predicted is the mean amount, for each of the nine cases, across all respondents. Thus, one $i$ will be no different than another. Later on, we report the results of a Level 2 analysis in which we do distinguish among individual respondents, by their answers to the demographic questions we asked. That is the method by which we ascertain, for example, whether men and women, or members of different political parties, answer the questions differently, and if so, in what ways. But before we get to that point, we must complete the basic Level 1 equation, for what we have above is not quite finished.

Finishing involves finding the values for the coefficients in the equation-the values that produce predicted support amounts for each case that are the closest to the actual mean values in the data (the "best fit" line). One can do that for Equation 1 as it is set out, and we did, but the best fit line still does not fit very well. If one were to reproduce Figure 1, but with Equation 1's predicted values rather than the actual means, the problem becomes obvious: the three lines (one for each maternal income) in this alternative version of Figure 1 do not fan out. They are parallel to one another. That is because the change in the support amount Equation 1 returns, for any given change in NRP's income, is the same no matter the PWC's income. One can see this from just inspecting the equation itself: the effect of any change in NRP income on the calculation of $\llbracket \mathrm{CSJ} \rrbracket_{\mathrm{ij}}$ depends on the coefficient for NRP income, and nothing else-and certainly not the PWC income. Under Equation (1), changes in PWC income certainly affect the predicted support 
amount, but only directly - they have no impact on the role that changes in NRP income have, as they do in the actual data. In statistical terms, what we need is a term in the regression equation for the "interaction" of the two parental incomes, in addition to the "main effect" that each parental income also has on its own. We must thus add an 'interaction term' to the formula. That term, $\left(b_{3}\left(P W C I n c_{j} * N R P I n c_{j}\right)\right)$, consists of the two incomes in case $j$ multiplied by one another, and by its own coefficient, $b_{3}$. Adding this interaction term to Equation (1) produces Equation (2):

$$
\operatorname{CSJ}_{i j}=b_{0}+b_{1} P W C I n c_{j}+b_{2} N R P I n c_{j}+b_{3}\left(P W C I n c_{j} * N R P I n c_{j}\right)+e_{i j}(2)
$$

Introducing this interaction term allows for the possibility that the slopes of the three lines (one line for each PWC income) are not parallel. The next step is to estimate the values for the coefficients, the constant, and the error term in this equation. There are various methods for doing this. We employ a modelling approach that readers familiar with statistical analysis know as 'hierarchical linear modelling', or HLM (Raudenbusch and Bryk, 2002). We make this choice because of the structure of our data: we wish to analyse how responses vary across the nine cases presented to each individual, but we also wish to make comparisons across individuals. This method allows one to compute essential statistics for data structured in this manner. Table 2 shows the results from this analysis of Equations (1) (without the interaction term) and (2) (with the interaction term). Figure 5 reproduces Figure 1, but using the values predicted by Equation (2) (the "fitted" values or amounts) rather than the raw means. One can see from the Table 2 that all the values, including the interaction term, are highly significant. (One tests for significance by identifying the probability that the result would arise from chance or random fluctuation. The smaller the probability, the more significant is the result. The column labelled "significance" in this table shows that the probability is zero through the third place after the decimal-a highly significant result.) One can see Figure 5 reproduces the fanning line pattern of Figure 1. We thus see that the model captures the raw data quite well. (The very sharp-eyed, or those with rulers, might have noticed that the data points in Figure 1 do not fall precisely on a straight line. In fact, quadratic terms were also statistically significant, but quite marginally so. They would have added considerably to the complexity of the model without providing much additional accuracy, and we therefore chose to proceed with the linear terms shown here.) 
We now go on to examine the insights into the data that the model reveals. Applying the HLM analysis explained in the boxed text yielded equations with the values set out in Table 2. Our focus is on the second equation. The table sets out the coefficients for each term in the model: the Intercept (sometimes called the Y-Intercept or constant term), the two parental incomes, and the interaction term in the equation which captures the fact that the effect of father's income on the child support amount depends in part of the level of the mother's income. The significance level, which is zero to three decimal places, tells us that the model fits the data very well. Figure 5 is the equivalent of Figure 1, but using the model's fitted values rather than the raw mean values.

Table 2 Child Support Judgements based on parental incomes (HLM) - basic model, with and without interaction term on incomes

\begin{tabular}{lrrrc}
\hline \multicolumn{1}{c}{ Variable } & Coefficient & Standard error & z-statistic & Significance \\
\hline \multicolumn{1}{c}{ Equation 1 } & & & & \\
Intercept & 132.2917 & 6.389 & 20.78 & 0.000 \\
PWC (Mother) income & -134.9099 & 2.389 & -56.46 & 0.000 \\
NRP (Father) income & 220.494 & 1.555 & 141.83 & 0.000 \\
\hline \multicolumn{1}{c}{ Equation 2 } & & & & \\
Intercept & -110.44 & 10.844 & -10.19 & 0.000 \\
PWC (Mother) income & 23.72 & 6.206 & 3.82 & 0.000 \\
NRP (Father) income & 342.11 & 4.662 & 73.39 & 0.000 \\
Interaction & -79.32 & 2.873 & -27.61 & 0.000 \\
(MotherIncome*FatherIncome) & & & & \\
\hline
\end{tabular}

$\mathrm{N}=22,725$ observations from 2,525 individuals (complete cases).

Models run in Stata v11.2's xtmixed. 


\section{Figure 5 Child support judgments as estimated from HLM Equation (2)}

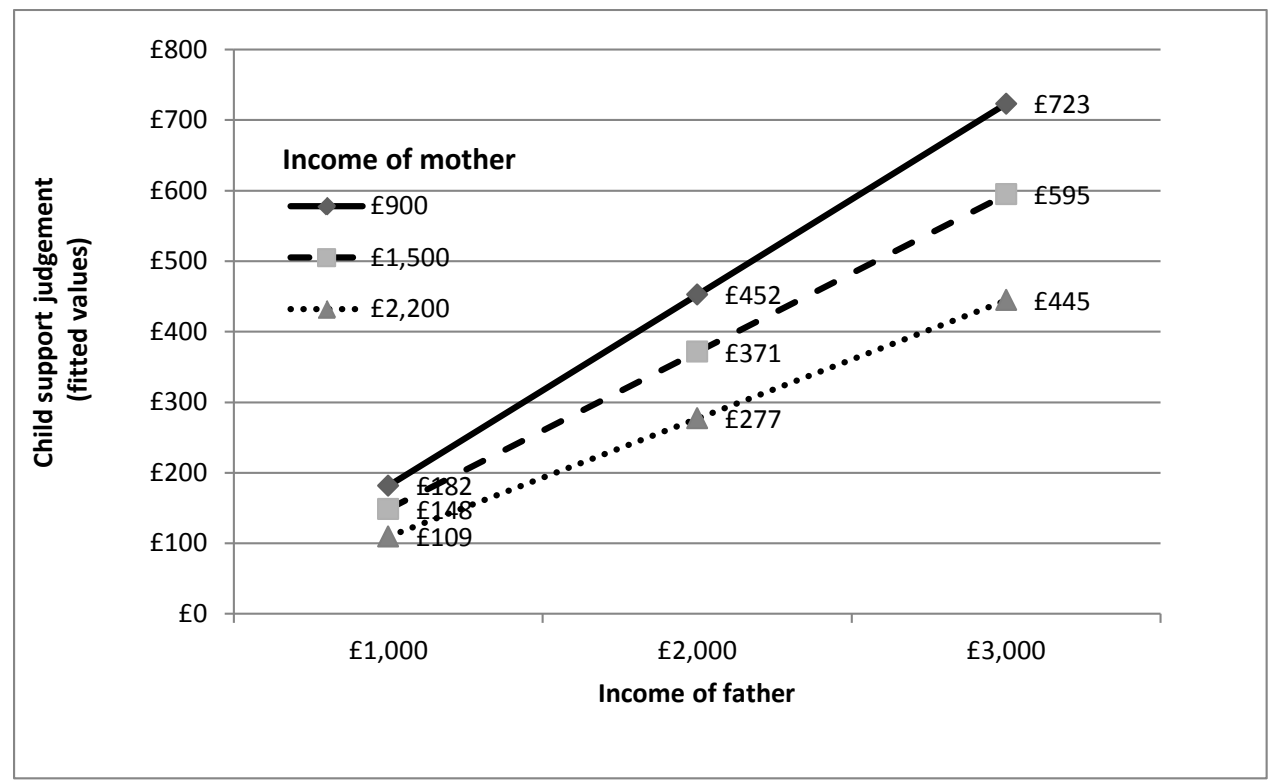

\section{Stability of the results}

How stable are our results? Figure 4 showed a considerable difference between the mean support amounts given by those in the highest and lowest quartiles. One would expect such variability in the answers to any question for which respondents have a limited frame of reference. Imagine, for example, asking a random sample of the public to estimate the cost of a bottle of a particular vintage of French burgundy from a particular vintner. The task given to our respondents surely involved matters that are more familiar to most of them, but one would still expect considerable variability. However, our repeated measures design - with nine responses for each respondent across the income variations - allows us to probe the relationship among the nine judgments given by any single respondent. That is one way of getting at the effect of the parental income alone on their judgment, once everything else is controlled for. Are the repeated judgments of each respondent also highly variable, or are they stably related to one another?

One way of answering this question is to calculate a simple correlation between any given respondent's answers. For example, the correlation between the first and second judgment given 
by a respondent was $r=0.72$, and between the second and the third, it was $r=0.83 .{ }^{19}$ One can thus be much more accurate in predicting a respondent's judgment for any particular case once one knows that respondent's judgment in a prior case. (In statistical terms, for those with the relevant background, knowing the respondent's first judgment lowers the standard error of estimate for the second judgment to 48 percent of its former value.) This suggests there is a coherent pattern to each individual's set of nine judgments, even if one individual's nine judgments are different from another's. The nine judgments are not random 'stabs in dark' but seem instead to reflect a thoughtfully constructed system for taking account of parental income.

A second way of examining the stability of the results is to compare the variability in the slope of the individual regression lines in Figure 5, to the variability in their Y-intercepts. The Yintercept - the value of the child support amount for the point at which the line would cross the vertical (Y) axis if it were extended-is determined by the value of the constant. It is usually referred to, as in Table 2, as simply the Intercept. The slope is determined by the coefficients for the parental income terms. The variability in all these terms is measured by their standard errors, and the third column of Table 2 shows that the standard errors for the income coefficients in Equation (2) are about half the size of the standard error for the Intercept. That means there is more variability in our respondents' choice of support amount in any single case than in how they adjust their initial answer in response to changes in parental income in subsequent cases (their own individual regression line slopes). Put another way, respondent A and respondent B might award very different support amounts in each case they consider - A may be more generous than B overall, so that A's responses would be plotted higher up a chart like figure 1 than B's - but the way that they each adjust their individual responses from case to case - and so the overall pattern of their responses - will be quite similar. Our respondents are remarkably consistent with one another in deciding the effect that any given change in either parent's income should have on the child support amount, even when they start with different amounts in the first case put to them. ${ }^{20}$ It is of course the way in which one adjusts support amounts in response to parental income changes that produces the fanning line pattern. This analysis thus confirms the visual impression conveyed by Figure 4, which showed that the support amounts favoured by those at both the upper and lower quartiles also form a fanning line pattern. This relative consistency with which the public favours this pattern is important because the pattern has policy implications, as we point out in the final section of this article. 
A third question is whether these results are likely to be replicated if the questions were put to a new sample of the public. The small size of the standard errors for all the terms in the equation tells us to expect a new sample would produce raw values close to those in this sample. The particularly small standard error for the coefficients for both the father income and the income-interaction term tells us the slopes of the lines in Figures 1 and 5 are unlikely to be very different, and the similarly small standard error for the coefficients of mother income and the interaction term means that the distance between the lines should also change very little across samples. The somewhat larger standard error for the Intercept means the height of the lines will vary more across samples, but whatever the height, the fanning line pattern persists. The stability of the fanning line pattern is also suggested by the fact that it is found within each of the demographic subgroups in our sample that we considered: age, gender, income, housing tenure, educational qualifications, and political affiliation. Some groups preferred slightly higher or lower support amounts, in general, than other groups, but all favoured the fanning line pattern. Further explanation of our findings about these demographic variables is presented in the next section.

\section{Differences among demographic subgroups}

One might wonder whether there were systematic differences in the child support judgments of different groups of respondents. The BSA survey included demographic information on the respondents, and we investigated seven attributes that one might expect to affect their child support judgments:

Age - are there systematic differences between the amounts favoured by older and younger respondents?

Gender and presence of children - do men and women set different amounts? Did having children of dependent age in the household make any difference?

Experience of child support system - are responses affected by the respondent's current or prior status as a payer or recipient of child support? This attribute is obviously very likely to overlap with gender.

Income - household income deciles. 
Housing tenure -in the UK, housing tenure is a reasonably good (and enduring) proxy for social position.

Educational qualifications. We compare those with degrees, to those without such qualifications.

Political affiliations. We consider if identifying with any of the main political parties affects child support judgments.

As explained in the boxed text, we employed Hierarchical Linear Models (HLM) to investigate this question, as this technique allows one to ask how within-subject variations (here, the changes in each respondent's support amounts across the nine income combinations), are affected by differences between subjects, such as their demographic characteristics. Each respondent's child support judgments in the nine cases are represented by the Level 1 equations set out in the box above; the respondents' varying demographic characteristics are added through Level 2 equations. This method allows us to ask whether these demographic characteristics affect either the absolute amount of the individual's support judgments (i.e., the Intercept, or height of the lines on the graph) or the way in which those judgments change with parental incomes (the slope of the lines on the graphs).

The results are shown in Table 3. The second column shows the Level 2 coefficients for each of the tested demographic characteristics; those with asterisks are statistically significant, with the significance level shown in the last column. Consider gender first. The simple descriptive analysis offered in our earlier article (Bryson et al. 2013) detected no difference in the responses of men and women, but the HLM analysis shows there is in fact a small but significant $£ 20$ increment in the support amounts favoured by women over those favoured by men. (This follows from the fact that the coefficient for "female" is 19.968, which we round to 20.) Plotting the 
Table 3 Child Support Judgements based on parental incomes (HLM two level regression) - main model.

\begin{tabular}{lccrc}
\hline Variable & Coefficient & Standard error & z-statistic & Significance \\
\hline Level 1 variables & & & & \\
Intercept & $-59.45^{*}$ & 26.078 & -2.28 & 0.023 \\
PWC (Mother) income & $23.73^{* * *}$ & 6.206 & 3.82 & 0.000 \\
NRP (Father) income & $342.11^{* * *}$ & 4.662 & 73.39 & 0.000 \\
PWCInc*NRPInc & $-79.32^{* * *}$ & 2.873 & -27.61 & 0.000 \\
Level 2 variables & & & & \\
Female & $19.698^{*}$ & & & \\
Ever received child support. & $-39.09^{* *}$ & 13.478 & -2.9 & 0.021 \\
Highest qual (ref=graduate) & & & & \\
Other quals & $-60.317^{* * *}$ & 11.578 & -5.21 & 0 \\
None & $-82.34^{* * *}$ & 14.443 & -5.7 & 0 \\
Political affiliation (ref=Lib & & & & \\
Dem) & & & & \\
Conservative & 17.427 & 18.46808 & 0.94 & 0.345 \\
Labour & 8.066 & 18.19054 & 0.44 & 0.657 \\
Other & -11.641 & 19.35981 & -0.6 & 0.548 \\
None & -25.066 & 19.99512 & -1.25 & 0.21 \\
Housing tenure (ref=owner) & & & & \\
Social tenant & -13.303 & 12.37974 & -1.07 & 0.283 \\
Private tenant & -7.567 & 12.18872 & -0.62 & 0.535 \\
Income deciles (ref =low) & & & & \\
2 & -18.15 & 19.4768 & -0.93 & 0.351 \\
3 & -7.767 & 18.99008 & -0.41 & 0.683 \\
4 & -5.098 & 20.06727 & -0.25 & 0.799 \\
5 & -23.228 & 20.28709 & -1.14 & 0.252 \\
6 & -3.944 & 20.59921 & -0.19 & 0.848 \\
7 & -7.883 & 21.1895 & -0.37 & 0.71 \\
8 & -8.104 & 20.55839 & -0.39 & 0.693 \\
9 & 13.896 & 21.85725 & 0.64 & 0.525 \\
Highest & 37.307 & 21.48991 & 1.74 & 0.083 \\
\hline & & & &
\end{tabular}

$\mathrm{N}=22,725$ observations from 2,525 individuals (complete cases).

Significance levels: $*=0.05, * *=0.01, * * *=0.001$. 
fitted support amounts for each gender in Figure 6 shows that the lines for women are consistently higher than those for men, but the gap between them is quite small. One can also see that there is no difference at all in the slope of the lines. So women start from a slightly higher point, but men and women change their support amounts in precisely the same way as parental incomes change. We note that the size of the gender gap was similar in the American studies, but in the U.S. there was also a small difference in slope: there, the gender gap in fitted support amounts was greater at higher father incomes than at lower ones (Ellman, et. al. 2009).

\section{Figure 6 Child support judgments (fitted values) for women and men.}

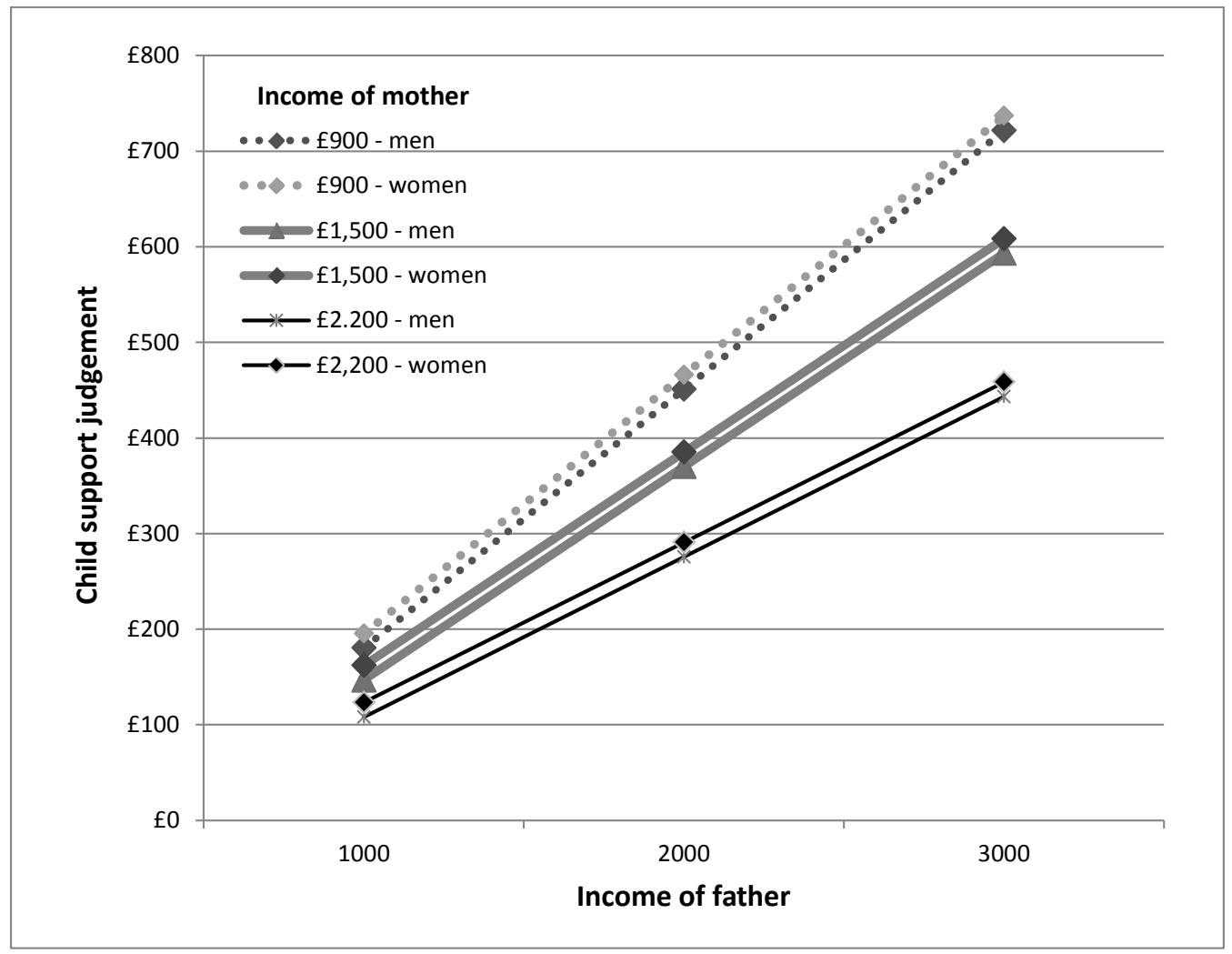

In each case the higher of the pair of lines is for women, and the lower line for men.

About three per cent of our respondents indicated that they had at some time made child support payments, and another three percent indicated that they had at some time received them. 
Those reporting they had paid support favoured support amounts no different from the rest of the respondents, but those reporting they had received child support favoured support amounts that (perhaps surprisingly) were about $£ 40$ lower. ${ }^{21}$ Their lower amounts were still usually higher, however, than the amounts set by the CSA formula, and they still varied with both father and mother income and thus produced the usual fanning line pattern. (Note that the lower amounts for Comment [IE1]: Aren't thjese fitted amounts, not raw averages? those who at some time had received support are independent of any income effect, as household income is also included in the model.) We have no ready explanation for this result, but it is important to note that non-resident fathers, and lone mothers, who do not say they had paid or received child support are not included in these figures, making them more difficult to interpret. ${ }^{22}$

Our respondents can be sorted into three levels of education: those with university degrees, those with secondary school qualifications (or equivalent) without university degrees, and those who claimed no formal qualifications of any kind. Other things being equal, university graduates proposed child support amounts that were around $£ 60$ higher than the middle group and $£ 82$ higher the least educated group. Figure 7 compares the university graduates to the least educated group. It shows the amounts that university graduates propose for mothers earning $£ 1,500$ and $£ 2,200$ per month were very similar to the amounts the least educated group propose for mothers earning $£ 900$ and $£ 1,500$, respectively. Simply looking at Figure 7 shows once again, however, that the slopes of the lines for university graduates, and for the least educated, are quite similar: while graduates propose higher absolute amounts, the two groups' adjustments of support amounts, in response to parental income changes, are quite similar. 
Figure 7 Child support judgments (fitted values) of university graduates and those with no formal credentials.

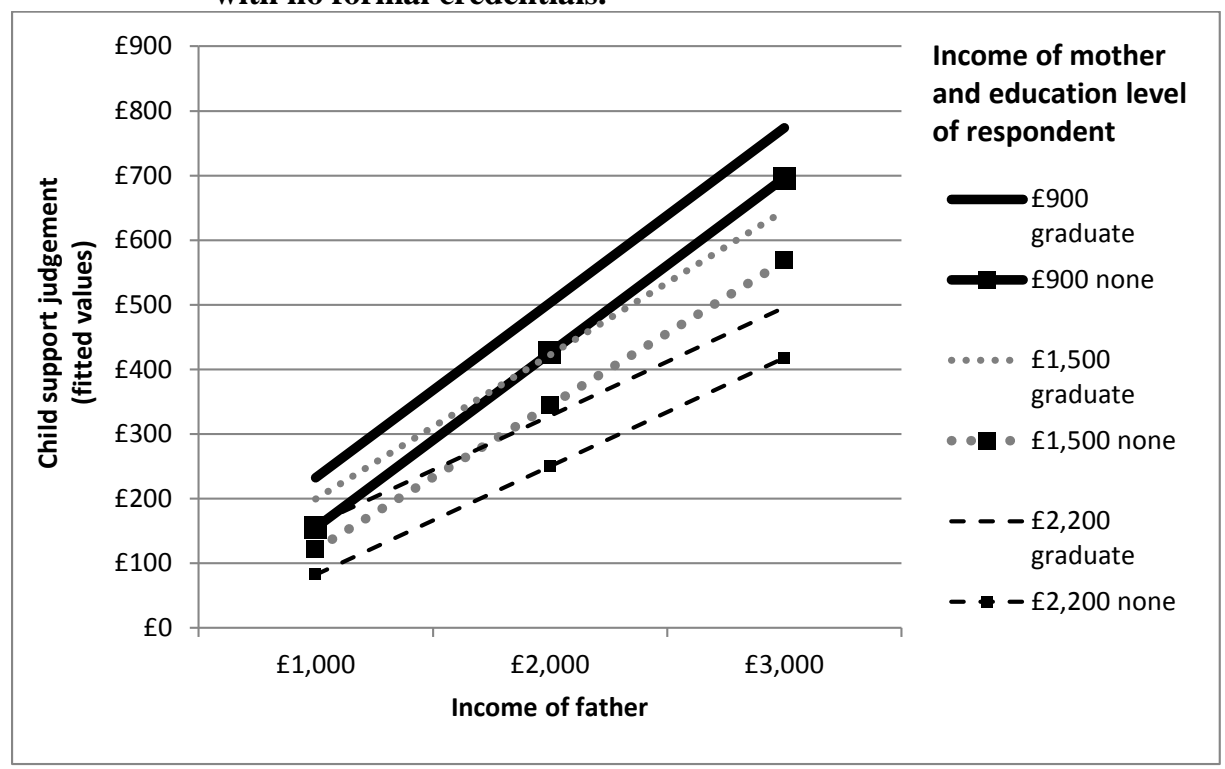

As one would expect, graduates' incomes are on average higher, but the higher support amounts they favour are also independent of any income effect. Indeed, and perhaps surprisingly, respondents' incomes were unrelated to their child support judgments. Other characteristics we examined, but which also had no effect on respondents' support judgments, were age and having a child in one's household. Table 3 also shows there was no statistically significant effect of either housing tenure or party political identity. Although the analysis is not included in Table 3, the small group asked to state the amount they thought fair ( $\mathrm{N}$ of 264) favoured slightly lower amounts than the main group asked the amount they thought the law should require ( $\mathrm{N}$ of 2984). ${ }^{23}$

\section{DISCUSSION}

Our earlier article (Bryson, Ellman, McKay and Miles 2013) reported on the Likert questions we put in the 2012 BSA survey (asking respondents to indicate their level of agreement or disagreement with statements about child support policy). It showed a majority of the public agreeing the government should set minimum support amounts, and, when necessary, should 
'force' a recalcitrant parent to pay. But how much support should the government require, and just what factors should matter in deciding on that amount? The data we present here paint a fairly clear picture of the British public's answers to these questions for the case we put to them: divorced parents with one child, an eight year old boy, who lives his mother but sees his father during the week and usually stays with him one night at the weekend. The fanning line pattern displayed in Figures 1 (the raw data means) and 5 (the HLM fitted amounts) shows the public believes the amount of support that the law should require the father to pay:

1. Should depend on both the father's income and the mother's income (since there are three lines).

2. Should increase with the father's income, all else being equal (since the lines slope up).

3. Should decline as the mother's income increases, all else being equal, not only in pounds but also as a percentage of the father's income (since the three maternal lines are not parallel, reflecting the fact that the lower the maternal income, the steeper is the line's slope).

4. Should continue to rise with the father's income beyond the point needed to ensure the child is not in poverty, thus permitting the child access to amenities as well (since the lines continue to rise with paternal income through the highest paternal income we asked about, for all three maternal incomes). One expects there is some level of affluence beyond which the public believes the support amount need not rise, but if so, that level was not reached in any of the cases we put to them.

Our confidence that these statements accurately portray the public's views has several bases. First, asking respondents to decide specific cases provides a more stable window into the principles they believe should apply than does asking about those principles directly. People are often unable to construct abstract statements of principle that accurately capture their intuitions about the fair way to decide concrete cases. One reason for that difficulty is that abstract propositions typically contain ambiguities in their application to specific cases. Inferring respondents' favoured principles from systematic patterns in their case decisions can eliminate ambiguities. That does not mean that what people say about principles has no meaning or importance. Indeed, the American studies that inspired this project found a clear, logical, and 
systematic relationship between the respondents' ratings of the principles and their decisions in the cases (Ellman, Braver, and MacCoun, 2012), results that a forthcoming article in this series will show are largely replicated in British context. In both the American and British studies, however, the respondents decided cases first and rated principles afterward, and a later American study found reason to believe their case judgments were more stable than their ratings of the principles. That study (Braver, Ellman, and MacCoun 2014) compared the responses of two groups of respondents. Both decided cases and rated child support principles, in questions quite similar to those put to our British respondents, but the sequence for one group was the reverse of the other's: one first decided the cases, while the other first rated the principles. The question was whether the sequence affected their choices in either task. The answer was that the sequence affected the respondents' ratings of the child support principles, but not their decisions in the cases. Those who first worked through the cases rated several principles differently than those who rated principles before seeing the cases, but there was no difference in the way respondents in the two groups decided the cases. Those results suggest people are more likely to conform their views about principles to their case decisions, than the other way around. These findings are consistent with earlier studies others conducted about other legal domains (Holyoak and Simon, 1999). ${ }^{24}$ So we believe the pattern of our respondents' case decisions provides the best single window into the principles they believe the law should reflect, although the full story would include the views about principles held by respondents who have also considered cases.

It is important that the four principles we infer from the respondents' case decisions are not dependent on the absolute levels of support they favour so much as on how they adjust support levels in response to changes in parental incomes. Viewing the data graphically, it is the slope of the lines, especially in relation to one another, from which these principles are inferred, rather than their heights. And it is just this pattern of slopes-the fanning line pattern seen in Figures 1 and 5-that is particularly robust. As explained above in Sections 3 and 4, not only is there reason to be confident that a repeated sampling of the entire British public would largely reproduce both Figures, it is also true that the basic fanning line pattern is reproduced if one looks only at demographic subgroups within the sample. Our key results, in another words, are not very dependent on whom we ask. One might still wonder, however, how much it depends on exactly what we ask and how we ask it. 
Data from the American studies, as well as other data collected in this study on which we will report in future articles, confirm that it does not depend much at all. Our respondents were all asked to set child support amount (across the same nine income combinations) for a second family situation in addition to the one we report on in this article. The 2,984 respondents were divided into 11 groups for this purpose, each group being asked about a different second family. Forthcoming articles will discuss in detail how the factual changes in the family situations affected our respondents' favoured support amounts, but for now we observe that the basic fanning line pattern was replicated in all these additional cases as well. Even more compelling evidence is offered by the American studies that developed the methodology borrowed for this project. Apart from one interesting difference in detail (which we address below), the answers of American respondents to essentially identical questions ${ }^{25}$ produced the identical fanning line pattern, not only in the original American experiment equivalent to this one (Ellman, Braver, and MacCoun, 2009), but repeatedly, across eight different variations that might be expected to, and usually did, change our respondents' preference as to the absolute support levels. (Braver, Ellman, and MacCoun, 2014; Ellman and Braver, 2011). Some variations involved different facts about the family (such as specifying that there are two children, not one, or that the parents were not married) and some involved differences in how the question is framed (such as asking respondents about fifteen different income combinations rather than nine, or asking them to choose a support amount from an array of possibilities, rather than asking for a free-form response, or by wording the question to emphasize that the payment is for the child, rather than that it is paid to the mother). In some (but not all) cases, the change produced best fit lines that were higher or lower, or slopes that were steeper or flatter, but the fanning line pattern persisted across all the cases, whether or not they exhibited these other changes.

In sum, the fanning line pattern found in this study is robust across demographic groups within the UK, across national boundaries, across population samples within the U.S., and across changes in either the facts of the question, or the way it is put. We are therefore confident the fanning line pattern would be replicated again with repeated samples of the British public, and therefore also confident the British public supports the four principles set out above that we infer from this pattern.

That said, we must also note one respect in which the UK responses differed from the American. Respondents in both countries would require fathers to pay a higher percentage of 
their income in child support when the mother's income is lower-the very reason why the three lines in Figures 1 and 5 are not parallel but fan out. But as noted above, the British public also favours requiring fathers to pay a higher percentage of their income in child support when their income is higher. American respondents, by contrast, tended to propose support amounts that were a relatively constant percentage of the father's income, for any given maternal income. Americans thus favoured rates that went up as maternal income declined, but did not change very much with paternal income. The effect, visually, is that while the results from both countries form a fanning line pattern, the slopes of the lines are steeper in the UK than in the U.S. This difference between the two countries persists across all the variations in the questions we have just noted, and would seem to reflect a greater appetite for income redistribution among the British than among Americans.

The conclusion seems thus inescapable that there are important features of current as well as proposed UK law that are inconsistent with the British public's firmly held values. The public believes the government should enforce the child support obligations of fathers at levels that are higher when mother income is lower, and that rise with father income well past the point at which the child escapes any risk of poverty. This latter finding is buttressed by the British public's preference (unlike the American public's) for support schedules that require fathers to pay a higher percentage of their income in child support when their income is higher, not just the higher amount one would get from applying a constant percentage. It thus seems clear they believe that children of higher-income fathers should enjoy some of the amenities the father is capable of providing, but which the mother is not. It is reasonable to wonder, then, why the British law is configured as it is. Answers, if not justifications, may perhaps be found in its history. Difficulties with the initial British support guidelines caused policymakers to make changes that put a premium on simplicity and ease of administration. Those are both fair concerns to be sure, but the reforms may have been too single-minded in pursuing them. The mother's income is if anything easier to obtain than the father's, and thus including it in the formula should not itself create important administrative challenges. Consider too the common assumption that guidelines should be based on the 'cost' of children, which the parents should presumably share. If one must fix support levels without considering both parents' incomes, then one has no basis for departing from a default assumption that the parents should devote the same 
percentage of their respective incomes to the children. But the implicit assumption of such a rule, that the mother is just as capable of providing for the child as the father, will usually be wrong.

Finally, the very focus on 'cost', while intuitively appealing, reflects conceptual confusion and is itself ultimately incoherent. One cannot say what a child costs without first deciding what to buy for her. To think of the child support obligation in 'cost' terms thus presumes that the question of what to buy has already been decided. Moreover, framing the question as 'what does a child cost' implies a single answer for all children. 'What does a child cost' is quite a different question than 'what does this child cost'. To many it suggests that what is called for is an estimate of the cost of providing a minimally adequate living standard that we would hope no child would fall below. That kind of cost estimate seems appropriate if the question is fixing the level of a public benefit meant to keep children from poverty. ${ }^{26}$ But is it an appropriate basis for a child support law? Only if one believes the father's responsibility is no greater than the state's, and the law's purpose is limited to requiring him to pay just enough to keep his children from suffering for lack of necessities. But that conception is obviously inconsistent with the public's views that the child support laws should require fathers to pay for amenities when they can afford to. It is indeed inconsistent with any support guideline, including the UK's, that increases the required support level with rising parental income, unless the guideline caps support amounts at very low levels. ${ }^{27}$ In fact, neither the UK guideline, nor any American guideline, is based on what children 'cost' in this sense. They are instead based on estimates of what parents in intact families spend on their children, and the guidelines go up with parental income because parents who have more money spend more on their children. ${ }^{28}$

Yet translating estimates of parental expenditures on children in intact families, into required support amounts in a child support guideline applied to separated families, is a tricky business involving many policy choices. (Ellman and Ellman, 2008; Ellman, 2013). It requires more than arithmetic. That is one reason why child support amounts vary, for example, among the American states: one state's formula may call for a support amount that is twice that which an adjoining state would impose for an identical case, although the discrepancy might be different for a second case (Pirog, Grieshop, and Elliot, 2003; Morgan and Lino, 1999). So the formulas vary within the U.S. as well as between the U.S. and the UK. The mechanical and precise nature of the support calculation creates the illusion that the numbers reflect some objective, scientific fact, when they actually reflect important policy choices about which people may differ. 
The most basic policy choice is deciding what counts as an 'expenditure on children'. The standard method (Ellman and Ellman 2008) imagines a hypothetical childless couple at some income level, and then asks how much more they would need to spend to maintain their living standard when a child or children are added to their household. But additional expenditures occasioned by the new child do not, of course, include things the parents also spent money on when childless, even though many of these continuing expenditures benefit the newly added children. So the cost of any changes in housing required to maintain the same living standardperhaps, for example, the additional cost of a larger home-counts as an expenditure on children, but the base cost of having a home in the first place does not. Such a system thus assumes the father should share, for example, in the additional cost of the extra bedroom, but not in the cost of the kitchen, bathroom, or living room, since the childless couples already had those. Additions to the food or clothing budget are counted, but not the cost of a car (except to the extent it is greater after children than before, which is not especially likely).

In short, the intact family makes many expenditures that confer benefits on children that are not included in the standard child expenditure estimates upon which most support guidelines are based, because they are 'joint expenditures' that benefit everyone in the household. ${ }^{29}$ The necessary premise of such a calculation is that the parents are equally capable, after separation, of providing the foundational living standard that the intact family enjoyed before separation, so that the child support system need only address how parents should share the additional expenditures the couple incurs by having a child. But where the mother earns less than the father, this premise is wrong. Providing her with the father's share of the cost of an extra bedroom does not help much if, now on her own, she cannot afford the rest of the home to which it is attached. A spousal maintenance order, if there were one, could deal with that discrepancy; a child support schedule based on estimates of 'child-only' expenditures, excluding joint expenditures that benefit children along with other household members, cannot.

When the two parents have relatively similar incomes, basing support amounts on childonly expenditures is not very problematic: in that case the parents face similar financial challenges from the separation, children aside. If they are in the same situation with respect to paying for the foundational household expenditures, it may make sense to focus exclusively on the additional expenditures occasioned by the children. But as the two parents' incomes become more disparate, the situation changes. The lower-income parent suffers a more precipitous drop in 
living standard from the separation than does the higher-income parent. And as the lower-income parent is most often also the mother with whom the child primarily lives, that steeper fall becomes a matter that the child support law should reasonably be expected to address. Of course, income transfers between parents through the child support system are not the only potential source of assistance for the low-income mother, and can in any event provide little real help in the common case in which the father is also low-income. Benefits provided through public programmes necessarily play a critical role. But they are alone often inadequate, and are not intended to and in fact cannot provide children of higher-income fathers with the amenities these children were accustomed to and some of which, at least, their fathers are still able to provide after separation.

A system requiring the father to pay his share of just the child-only expenditures might be explained as maintaining the status quo: he is then contributing, after separation, precisely the same amount toward his children that he did before separation. But it is the same amount of only the additional 'child-only' expenditures. He retains all he contributed to the foundational joint expenditures, even though these must be duplicated after separation when the parents need two kitchens rather than one. In effect, this system shields the higher-income father from contributing his share to the duplicated costs that are the inevitable consequence of separation, leaving the lower-income mother to bear them on her own.

The differences between current British policy, and the policy favoured by the British public, is summarized in Table 4. 
Table Four. Comparison of the public's policy preferences with the policy choices implemented by UK law.

\begin{tabular}{|l|l|}
\hline \multicolumn{1}{|c|}{ The UK Public's Policy } & \multicolumn{1}{|c|}{ The UK Public Policy } \\
\hline $\begin{array}{l}\text { Low-income mother receives more support } \\
\text { than higher-income mother, thus helping her } \\
\text { with basic living expenses }\end{array}$ & $\begin{array}{l}\text { Low-income mother left on her own with } \\
\text { respect to basic living expenses. }\end{array}$ \\
\hline $\begin{array}{l}\text { High-income father pays a higher rate than } \\
\text { low-income father }\end{array}$ & $\begin{array}{l}\text { High-income father pays same rate as low- } \\
\text { income father (UK), often less in U.S. }\end{array}$ \\
\hline $\begin{array}{l}\text { High-income father contributes enough to } \\
\text { provide some amenities }\end{array}$ & $\begin{array}{l}\text { Amenities in mother's household depend } \\
\text { primarily on mother's income }\end{array}$ \\
\hline Parents share the cost of separation & $\begin{array}{l}\text { Father is protected from sharing the extra costs } \\
\text { created by separation }\end{array}$ \\
\hline
\end{tabular}

In sum, the intuitions of the British public offer important insights into the design of the child support calculation, insights that the current UK law's history may have led its draughtsmen to miss. The mother's income matters, and, especially when parental incomes are disparate, more should probably be expected from the higher-income father than the law currently requires. That is certainly the view of the British public, and it appears to be a view to which policymakers ought to give considerable attention. The importance of this point is of course connected to the role that the statutory formula plays in the system. One consistent difference between the U.S. and the UK is the formula's legal effect. In the U.S. child support is always set in a judicial order, and the judge must justify, in writing, any deviation of the order from the formula amount. The parents' agreement on the deviation is, in principle, alone insufficient to justify it. ${ }^{30}$ (So, for example, more than the parents' agreement is needed to justify a zero order, or one for only a token amount). In contrast, while the UK formula applies to child support arrangements made under the statutory system, even now more than half of child support payments are based on 'voluntary agreements' to which the formula does not apply - parents may choose to consult it, to apply it to their own cases, or to ignore it, or indeed they may negotiate entirely unaware of its existence. There is no official verification or accreditation of their agreements. ${ }^{31}$ It also remains true that many of those potentially 'entitled' to receive child support receive nothing, whether through lax enforcement or lack of applying for it. The importance of the formula will decline if even more parents are shifted into 'family-based' arrangements to which it will not apply. Yet that move would only increase the discrepancy between the law and the public's values. As our earlier article reported, the public strongly favours government enforcement of the child support 
obligation. That finding is fortified by the data we report here, which show strong public support for a revised formula that would require higher-income fathers to provide more support than the current formula provides. 


\section{REFERENCES}

Ariely, D, Loewenstein, G., and Prelec, D., (2003). 'Coherent Arbitrariness: Stable Demand Curves Without Stable Preferences,' Quarterly Journal of Economics 118,(1), 73-105.

Braver, S., Ellman. I., and MacCoun, R. (2014). 'Public Intuitions About Fair Child Support Allocations: Converging Evidence for a 'Fair Shares' Rule,, in press (to appear in volume 20, No. 2, of Psychology, Public Policy, and Law, May 2014).

Braver, S., MacCoun, R., and Ellman, I.M, (2008). 'Converting Sentiments to Dollars: Scaling and Incommensurability Problems in the Evaluation of Child Support Payments', paper presented to the Third Annual Conference on Empirical Legal Studies, 2008, available at http://papers.ssrn.com/sol3/papers.cfm?abstract_id=1121240

Bryson, C., Ellman, I., McKay, S. and Miles, J. (2013). 'Child maintenance: how much should the state require fathers to pay when families separate?' British Social Attitudes 30, published on line at http://www.bsa-30.natcen.ac.uk/media/36317/bsa30_child_maintenance.pdf.

Daniels, N. (1996). Justice and justification: Reflective equilibrium in theory and practice. New York, NY: Cambridge University Press.

Ellman, I.M. (2004). Fudging Failure: The Economic Analysis Used to Construct Child Support Guidelines, University of Chicago Legal Forum 2004, 162-224.

Ellman, I.M., and Braver, S.L. (2011). 'Lay Intuitions About Child Support and Marital Status', Child and Family Law Quarterly 23, 465-488.

Ellman, I.M., Braver, S.L., and MacCoun, R.J. (2012). 'Abstract Principles and Concrete Cases in Intuitive Lawmaking’, Law and Human Behavior 36:2, 96-108. 
Ellman, I.M., Braver, S.L., and MacCoun, R.J. (2009). 'Intuitive Lawmaking: The Example of Child Support', Journal of Empirical Legal Studies 6, 66-109.

Ellman, I.M., and Ellman, T.O. (2008). 'The Theory of Child Support', Harvard Journal on Legislation 45, 107-164.

Ellman, I. Kurtz, P., Weithorn, W., Bix, B., Czapanskiy, K., and Eichner, M., (2010). Family Law: Case, Text, Problems (5 ${ }^{\text {th }}$ Edition), San Francisco: Lexis-Nexis.

Holyoak, K. and Simon, D. (1999). 'Bidirectional reasoning in decision making by constraint satisfaction’. Journal of Experimental Psychology: General, 128, 3-31.

Kahneman, D., Schkade, D., and Sunstein, S. (1998). 'Shared Outrage and Erratic Awards: the Psychology of Punitive Damages’, Journal of Risk and Uncertainty 16, 49-86.

Morgan, L. W., and Lino, M. C. (1999). 'A comparison of child support awards calculated under states' child support guidelines with expenditures on children calculated by the U.S. Department of Agriculture,' Family Law Quarterly 33:1, 191-218.

Pirog, M., Grieshop, T., and Elliot, B. (2003). 'Presumptive state child support guidelines: A decade of experience'. Policy Currents, 12, 16-32.

Raudenbusch, S. and Bryk, A. (2002) 'Hierarchical Linear Models: Applications and Data Analysis Methods’, London: Sage Publications

Wissler, R.L , Hart, A.J., and Saks, M. (1999). 'Decision-making about General Damages: A Comparison of Jurors, Judges, and Lawyers’, Michigan Law Review 98, 751-826.

\section{NOTES}


${ }^{1}$ The child support system is gender-neutral - a non-resident mother is obliged to pay child support to a father with care. However, over nine cases in ten involve a resident mother and a non-resident father. For ease of exposition, we therefore often refer to the PWC (parent with care) as the mother, and the NRP (non-resident parent) as the father.

${ }^{2}$ Department for Work and Pensions, The Child Maintenance and Enforcement Commission and the Child Support Agency's Operational Improvement Plan, The Third Report of the Work and Pensions Committee Session 2009-10 [2010], HC118, at www.publications.parliament.uk/pa/cm200910/cmselect/cmworpen/118/118.pdf.

${ }^{3}$ National Audit Office Child Support Agency- Implementation of the Child Support Reforms, [2006] National Audit Office, London: The Stationery Office, HC 1174, available at: www.nao.org.uk/wpcontent/uploads/2006/06/05061174.pdf.

${ }^{4}$ From July 2013 the new formula based on gross income applies to applicants with two or more children for legal aspects see http://www.legislation.gov.uk/uksi/2013/1860/body/made and for broader discussion see http://www.familylawweek.co.uk/site.aspx?i=ed113401.

${ }^{5}$ Some sources of income, such as payments from pensions, are deducted before arriving at the relevant taxable gross income for calculating child support amounts.

${ }_{6}^{6}$ The gross income schedule will assess the father $12 \%, 16 \%$, and $19 \%$ for one, two, or three or more children, respectively, for incomes of up to $£ 800$ per week, dropping to $9 \%, 12 \%$ and $15 \%$ for amounts above $£ 800$ per week. This reflects (very roughly) the point at which the marginal income tax rate increases from $20 \%$ to $40 \%$.

${ }^{7}$ Department for Work and Pensions, Recovering child support: routes to responsibility, [2006] Cm 6894, London: The Stationery Office, available at: www.dwp.gov.uk/docs/henshaw-complete22-7.pdf.

8 'Income' was defined for the respondents by this sentence: 'By income, I mean their entire income after tax, including any wages, tax credits, state benefits and any other money coming into the household.'

${ }^{9}$ These figures were designed to be at the lower end, roughly in the middle, and towards the top $20 \%$, for the kinds of individuals discussed. So the lowest father income is based on full-time work at the national minimum wage, whilst the lowest mother's income was based on the level of means-tested social assistance ('Income Support' in the UK) plus a low level of means-tested support for rent and local taxes. The middle income figure for each parent was the gender-appropriate median wage, and the high income figure was around the 80th percentile wage for each gender.

${ }^{10}$ We note that respondents were divided randomly into 11 subgroups; each subgroup was asked an additional set of questions employing the same nine income combinations, but with a different set of facts about the family's situation. Data from these additional vignettes will be presented in future papers.

${ }^{11}$ For this group, the last three sentences in the first paragraph of the question as set forth in the box were replaced by these two sentences: 'But the question is how much maintenance is fair to expect the other parent to pay. There are no right or wrong answers on this. We just want to know the amount you think is fair.' The second paragraph was replaced by a different paragraph with only these two sentences: 'I'm going to tell you about several different situations, and ask you how much maintenance you believe it is fair to expect the parent to pay in each case.'

${ }^{12}$ Respondents answer a series of different modules, some of which are answered by one or two-thirds of the sample. All respondents were asked three modules about public spending and social security; transport, and child support. However, some also answered on end of life care, disability, or health. General sections, asked of all respondents, dealt with classifying respondents, job details, certain behaviours (e.g. newspaper readership) and attitudes (e.g. political support).

${ }^{13}$ Only 1988 and 1992 have been missed out.

${ }^{14}$ There were 264 additional interviews in the smaller group asked to state the support amount that was fair, rather than the amount they thought the law should require.

${ }^{15}$ Obviously, this view was not held by every respondent. In fact, while $73 \%$ adjusted their child support amounts when the mother's income changed, $27 \%$ did not. By comparison, only $6 \%$ did not adjust their support amount when the father's income changed. Both 'didn't change' figures (27\% and 6\%) include the $3.5 \%$ who gave the same answer to all nine questions, no matter either parent's income. And that $3.5 \%$ includes the $.5 \%$ who would not require any child support in any case. 
${ }^{16}$ Of course, one cannot assume this pattern would continue indefinitely through the very highest paternal incomes. From these data we cannot tell the point at which our respondents might 'top off' their required maintenance payments, other than that it is higher than the highest incomes we asked about.

${ }^{17}$ Here, and elsewhere, the comparison is to the CSA 2003 formula.

${ }^{18}$ Alternative rules apply below a gross income of $£ 200$ per week (£867 per month) and there is a ceiling set at $£ 3,000$ per week (£13,000 per month) where more income does not affect the calculated maintenance.

${ }^{19}$ Correlations range from -1 to +1 . A correlation of zero means two variables are completely unrelated to one another-knowing the value of one gives you no information about the value of the other. A correlation of +1 means that the two variables move up and down in value in perfect synchrony: every time one moves up $\mathrm{X}$ units, the other moves up Y units, so that you could predict a change in either one, knowing the other, with perfect accuracy. A correlation of -1 is an equally perfect predictor, but in this case one variable moves down $\mathrm{X}$ units every time the other goes up Y units. The positive correlations here are quite high, signifying strong predictive value.

${ }^{20}$ This phenomenon has been seen in other domains as well when citizens are asked to make judgments on matters for which absolute norms are not readily accessible, and has been called 'coherent arbitrariness' (Ariely, Lowenstein, and Prelac, 2003). For example, studies have found a high level of agreement among jurors as to relative culpability of tort defendants against whom punitive damages are claimed, and the relative severity of the appropriate punishment each should suffer, but great variability in the absolute amount of the appropriate dollar award. (Kahneman, Schkade, and Sunstein, 1998). Analogous results are found for jurors in tort cases asked to fix damages for pain and suffering (Wissler, Hart, and Saks, 1999).

${ }^{21}$ We originally analyzed separately the effect of having received or paid child support, and of having been an NRP or a PWC, but models would not run with both sets of terms included because of the strong overlap between them (e.g., having been an NRP is strongly correlated with having paid child support).

${ }_{22}$ There is reason to guess that many fathers who have not paid support also do not self-identify as NRPs. Surveys typically find about half as many NRP fathers as one would expect, given the number of self-identified lone mothers. One might expect the support amounts proposed by those experienced with the current support rules to be be closer to the CSA amount (and thus lower) because of a tendency to accept familiar rules, whatever they are, as appropriate. We know from the American studies, for example, that there is a significant anchoring effect when respondents asked to choose the support amount they believe fair are told that 'some courts' would order a specified support amount, even though 'other courts' differ. Such information shifts respondents' judgments towards the amount they are told 'some courts' would order, whether that anchor is higher or lower than the mean of respondents given no anchor point. (Braver, MacCoun, and Ellman, 2008). But we cannot explain why that anchoring would be seen here for those who had received support, but not for those who had paid it.

${ }^{23}$ The fitted amounts for the "fair to pay" group were about $£ 23$ less than for those who were asked our standard question, a difference not much more than the difference between men and women (£20), and considerably smaller than the difference between graduates and those with a lower level of qualification (about £60). The fair to pay group had an overall mean of $£ 355$, with a 95\% confidence interval of $£ 340$ to $£ 370$ (which roughly means there is a $95 \%$ chance the true mean lies between these points; for a more precise explanation of a confidence interval, see http://handbook.cochrane.org/chapter_12/12_4_1_confidence_intervals.htm) while for the other respondents the mean was $£ 378$, with a $95 \%$ confidence interval, $£ 372$ to $£ 383$, that is smaller because of the much larger $N$. One might have expected any difference, if there was one, to have been in the opposite direction, with some respondents perhaps believing there were philosophical or practical problems with the forcing fathers to pay all that one might believe a father, in fairness, should pay. We have no idea why any respondents would believe the law should require fathers to pay more than the respondent thought fair. Of course, we do not have a within-subjects comparison; respondents were not asked both the amount they thought fair and the amount they thought the law should pay. Our comparison is rather between the small group asked about fairness and the larger one asked about what the law should require. Had we asked some respondents about both, thus focusing their attention on the difference between the questions, we might not have found any difference. We cannot know. For this reason, as well as the fact that the difference was small, barely achieving statistical significance, we do not comment further on this result.

${ }^{24}$ It is also consistent with the assumptions underlying the classic American law school teaching method, in which students who identify a principle they believe explains the result in a particular case are then challenged to refine it by presenting them with a new case in which their initial formulation seems to call for an unjust result. Had we given our respondents the opportunity to reconsider both of their responses, our respondents might have adopted the process philosophers call reflective equilibrium (Daniels, 1996), in which they go back and forth between cases and principles, their answers to each helping to refine their views on the other. 
${ }^{25}$ This study recast the questions used in the U.S. only to achieve UK cultural equivalence.

${ }^{26}$ For a study of this kind in the UK, developed just for this sort of purpose, see Donald Hirsch, The Cost of a Child in 2013 (Child and Poverty Action Group, London, 2013), available at http://www.cpag.org.uk/content/costchild-2013.

${ }^{27}$ This study found no evidence of support for such caps in our respondents' proposed amounts, as they would require the highest-earning fathers we asked about, at $£ 3000$ a month, to pay a higher percentage of their income in support than they asked of lower-income fathers. While the American respondents did tend toward requiring fathers to pay a flat percentage of their income for any given maternal income level, rather than a percentage that rose with paternal income, they maintained such a flat percentage through the highest paternal incomes put to them, which reached $\$ 12,000$ a month net of taxes

${ }^{28}$ This is clear in the case of American guidelines; see Ellman and Ellman (2008). The basis of the UK guidelines is rather more mysterious. See note 25 , infra.

${ }^{29}$ For a detailed examination of how this works in setting American guidelines, see Ellman (2004). The basis of the current UK schedule is less transparent. It appears, however, that while the method may not be identical, it relies on the same key assumption that one should count only expenditures that benefit the child only, excluding joint expenditures that benefit all members of the household including the child. The relevant government report states that 'the proposed base rate of 15 per cent of their income is roughly half the average that an intact two-parent family spends on a child'. DSS, A new contract for welfare: children's rights and parents' responsibilities, Cm 4349, London, DSS (1999), at page 9. For this figure, the report cites Middleton, Ashworth and Braithwaite, Small fortunes: spending on children, childhood poverty and parental sacrifice, Joseph Rowntree Foundation, York (1997). This study involved a survey of families, both intact and lone-parent, who were asked about particular categories of possible expenditures on children, such as food, clothing, nappies, Christmas presents, etc. There are no joint expenditures among the items parents were asked about, just expenditures on items solely for the children. Whether the total of these 'child-only' expenditures equaled thirty percent of the income of the reporting families is less clear; the published study itself offers no measure of that kind at all, whether 30 per cent or some other figure. Most puzzling, however, is the logic of the assertion in the government report: if the child support schedule is to be based on an estimate that parents in intact families together spend 30 percent of their joint income on their children, one would expect the schedule to require the father to continue contributing 30 percent of his income after the separation. The DSS report provides no further explanation.

The 15 per cent figure endorsed by the report is applied to net income; the current plan is to change it to the roughly equivalent figure of 12 per cent of gross income. Compare Wisconsin, which like the UK (but unlike most American states) calculates child support on the basis of the father's income alone. Its rate for one child is 17 per cent of gross income. See http://dcf.wisconsin.gov/bcs/order/guidelines.htm. That is nearly half-again the UK rate.

${ }^{30}$ The basic federal rule all states must follow is set out in 45 C.F.R. $\$ 302.56$. It requires all states to have guidelines that set the specific dollar amount of a child support in all cases, and goes on to provide that the order must be for that amount unless there is a 'written finding or specific finding on the record of a judicial or administrative proceeding...that the [guideline amount] would be unjust or inappropriate in a particular case,....as determined under criteria established by the State. Such criteria must take into consideration the best interests of the child. Findings that rebut the guidelines shall state the amount of support that would have been required under the guidelines and include a justification of why the order varies from the guidelines.'

${ }^{31}$ Another difference is that Federal law in the U.S. requires the court to couple every child support order with a wage assignment order to the obligor's employer. Ellman et al, 2010:580-581. When the father is employed the formula's impact is thus inescapable, because he never sees the money it calls for. His employer must instead send that portion of his wages directly to the local child support enforcement agency, which then disburses it to the mother (assuming the state does not have first claim to it, as reimbursement for payments to the mother under the American welfare scheme). There is no such scheme in the UK. 